\title{
Platelets are activated in ANCA-associated vasculitis via thrombin-PARs pathway and can activate the alternative complement pathway
}

Di Miao 1,2,3,4,5, Dan-Yang Li ${ }^{1,2,3,4}$, Min Chen ${ }^{1,2,3,4^{*}}$ and Ming-Hui Zhao ${ }^{1,2,3,4,5}$

\begin{abstract}
Background: In this study, we investigated the mechanism of platelet activation in patients with antineutrophil cytoplasmic antibody (ANCA)-associated vasculitis (AAV), as well as the activation of the alternative complement pathway by platelets in AAV.

Methods: CD62P and platelet-leukocyte aggregates in AAV patients were tested by flow cytometry. Platelets were stimulated by plasma from active AAV patients. The effect of the thrombin-protease-activated receptors (PARs) pathway was evaluated by blocking thrombin or PAR1 antagonists. After platelets were activated by plasma from AAV patients, Ca/Mg-Tyrode's buffer and Mg-EGTA buffer were used to measure complement activation in liquid phase and on the surface of platelets.

Results: The levels of CD62P-expressing platelets and platelet-leukocyte aggregates were significantly higher in active AAV patients than those in remission and normal controls. Platelets were activated by plasma from active AAV patients (percentage of CD62P-expressing platelets, $97.7 \pm 3 \%$ vs. $1 \pm 0.2 \%, p<0.0001$, compared with those incubated with healthy donor plasma), and this was inhibited by thrombin or PAR1 antagonists (percentage of CD62P-expressing platelets, $97.7 \pm 3 \%$ vs. $2.7 \pm 1 \%, p<0.0001,97.7 \pm 3 \%$ vs. $5 \pm 1.4 \%, p<0.0001$, respectively). Platelets activated by plasma from AAV patients could trigger complement activation via the alternative pathway, as demonstrated by significant elevation of $\mathrm{C} 3 \mathrm{a}, \mathrm{C} 5 \mathrm{a}$, and sC5b-9 and significantly more C3c and C5b-9 deposition on the surface of platelets.
\end{abstract}

Conclusions: Platelets were activated in AAV patients, and such activation was at least partially attributed to the thrombin-PARs pathway. Activated platelets triggered the alternative complement pathway in AAV.

Keywords: ANCA, Vasculitis, Platelets, Thrombin, Protease-activated receptors, Complement

\section{Background}

Antineutrophil cytoplasmic antibody (ANCA)-associated vasculitis (AAV) comprises a group of autoimmune diseases that mainly affect small vessels, including microscopic polyangiitis (MPA), granulomatosis with polyangiitis (GPA) and eosinophilic granulomatosis with polyangiitis (EGPA). The two major antigens in ANCA

\footnotetext{
* Correspondence: chenmin74@sina.com

${ }^{1}$ Renal Division, Department of Medicine, Peking University First Hospital, Beijing 100034, China

${ }^{2}$ Institute of Nephrology, Peking University, Beijing 100034, China Full list of author information is available at the end of the article
}

are myeloperoxidase (MPO) and proteinase 3 (PR3). Cumulative evidence suggests that complement system activation via the alternative pathway is indispensable for the development of AAV [1-3]. The mechanism of alternative complement pathway activation in AAV is not fully understood, and it is mainly considered to be a downstream effect of neutrophil activation $[1,4,5]$.

Increasing studies demonstrate a high prevalence of venous thromboembolic event (VTE) and a hypercoagulant state in AAV patients [6-11]. In the active stage of $\mathrm{AAV}$, the platelet count is usually elevated $[10,12]$. In addition to their classic hemostatic role, platelets are 
also inflammation protagonists [13-16]. Platelets and the soluble molecules that they secrete can mediate inflammatory responses and thus contribute to vascular injury $[17,18]$. An association between some platelet indices, including platelet counts, mean platelet volume, and disease activity have been reported in AAV and several other autoimmune diseases, such as inflammatory bowel disease, ankylosing spondylitis and rheumatoid arthritis [10, 12, 19-21].

Thrombin, the main effector protease in the coagulation cascade, is one of the most potent platelet activators [22, 23]. Activation by thrombin initiates platelet degranulation and secretion, which translocates adhesion receptors to the cell surface, and releases hemostatic and inflammatory agonists/mediators into circulation, then causes surface molecule expression facilitating cellular adhesion [24]. Platelet activation by thrombin depends, at least in part, on signal transduction mediated by a family of G protein-coupled protease-activated receptors (PARs) in many diseases.

Our recent study demonstrated that the treatment of C5a-primed neutrophils with ANCA resulted in the release of tissue factor (TF), which subsequently led to thrombin generation [11]. We hypothesize that platelets are activated in AAV patients via the thrombin-PARs pathway, and such activated platelets can subsequently activate the alternative complement pathway in AAV.

\section{Methods}

\section{Detection of platelet activation by flow cytometry}

We analyzed the platelet activation parameters in AAV patients by flow cytometry, including CD62P and platelet adhesion to neutrophils, lymphocytes, and monocytes.

Blood samples were freshly collected from 31 patients with active AAV before the initiation of immunosuppressive therapy. Blood samples of 27 patients with AAV, who achieved complete remission at least 3-6 months after the initiation of immunosuppressive therapy, were also collected at their regular ambulatory visits. All the AAV patients in the current study met the 2012 revised Chapel Hill Consensus Conference criteria for AAV [25]. Disease activity was evaluated by the Birmingham Vasculitis Activity Score (BVAS) [26]. "Remission" was defined as "absence of disease activity attributable to active disease qualified by the need for ongoing stable maintenance immunosuppressive therapy" (complete remission), or "at least $50 \%$ reduction of disease activity score and absence of new manifestations" (partial remission) [27]. The BVAS levels of all the AAV patients in remission stage in this study were 0 .
Treatment protocols have been described previously $[28,29]$. In brief, induction therapy included corticosteroids in combination with cyclophosphamide (CTX). Oral prednisone was prescribed at an initial dosage of $1 \mathrm{mg} / \mathrm{kg} /$ day for 4-6 weeks, with reducing doses over time to $12.5-15 \mathrm{mg}$ by 3 months. CTX was administered by daily oral dose of $2 \mathrm{mg} / \mathrm{kg} / \mathrm{day}$ or intravenously $0.5 \mathrm{~g} / \mathrm{m}^{2}$ every month. Patients with acute renal failure or pulmonary hemorrhage received three pulses of intravenous methylprednisolone (7-15 $\mathrm{mg} / \mathrm{kg} /$ day) before the standard induction therapy. Patients with severe pulmonary hemorrhage or acute renal failure requiring dialysis at diagnosis received additional plasma exchanges. For maintenance therapy, daily oral azathioprine (AZA) was given (2 $\mathrm{mg} / \mathrm{kg} /$ day) for at least 2 years.

Additionally, the blood samples of 40 healthy blood donors were also collected as normal controls. No VTE was observed by the time of blood collection, and none of the patients or healthy donors was receiving anticoagulant or antiplatelet therapies.

Citrate anticoagulated blood from patients and healthy donors were dispensed into an antibody cocktail containing CD41a APC (BD Pharmingen, San Jose, CA, USA), CD62P BV421 (BD Horizon ${ }^{\mathrm{m}}$ ) and CD45-APC-H7 (BD Pharmingen) incubated for 15 min and analyzed by flow cytometry. CD41a-APC was used to gate platelets. As CD62P is a typical marker of platelet $\alpha$-granule degranulation and lysosome degranulation, it serves as a marker of platelet activation [30-32]. Neutrophils, lymphocytes and monocytes were identified based on their characteristic light scatter, and differential CD45 expression [33].

\section{Isolation of platelets}

Platelets were isolated according to the methods described previously [30]. Briefly, blood was drawn from healthy donors, using a $21 \mathrm{G}$ or larger bore needle and a light tourniquet, into a sodium citrate vacutainer. Platelet-rich plasma (PRP) was formed by centrifugation at $200 \times \mathrm{g}$ for $15 \mathrm{~min}$ and then washed using a citrate wash buffer $(11 \mathrm{mM}$ glucose, $128 \mathrm{mM} \mathrm{NaCl}$, $4.3 \mathrm{mM} \mathrm{NaH} \mathrm{PO}_{4}, 7.5 \mathrm{mM} \mathrm{Na}_{2} \mathrm{HPO}_{4}, 4.8 \mathrm{mM} \mathrm{Na}_{3}$ $\mathrm{C}_{6} \mathrm{H}_{5} \mathrm{O}_{7}, 2.4 \mathrm{mM} \mathrm{C} \mathrm{C}_{6} \mathrm{H}_{8} \mathrm{O}_{7}, 0.35 \%$ BSA, $50 \mathrm{ng} / \mathrm{mL}$ prostaglandin PGE1, $\mathrm{pH}$ 6.5) [30]. Platelets were pelleted by centrifugation at $1200 \times \mathrm{g}$ for $10 \mathrm{~min}$ and resuspended in modified Tyrode's buffer (Leagene), as previously described [34].

\section{Stimulation and inhibition assays}

Heparinized plasma samples from 14 active AAV patients and 14 patients with minimal change disease (MCD, as the disease control) were collected 
immediately after centrifugation at $2000 \mathrm{~g}$ for $15 \mathrm{mi}$ nutes at $4{ }^{\circ} \mathrm{C}$. Then, the plasma was aliquoted and stored at $-80{ }^{\circ} \mathrm{C}$ until use. Repeated freeze/thaw cycles were avoided.

Platelets that were resuspended in modified Tyrode's buffer were incubated at $37{ }^{\circ} \mathrm{C}$ for 15 min with plasma from patients at a final concentration of $50 \%$. This concentration was chosen because it demonstrated the highest platelet activation in our pilot experiments. According to the previous study, $1 \mathrm{mM}$ Gly-Pro-Arg-Pro (GPRP, Sigma-Aldrich, St. Louis, MO, USA) was added to prevent fibrin polymerization [35]. To investigate the potential role of the thrombin-PARs pathway in platelet activation by plasma from AAV patients, plasma was pretreated with $20 \mu \mathrm{M}$ D-Phe-Pro-Arg- $\mathrm{CH}_{2} \mathrm{Cl}$ (PPACK, EMD Millipore, Billerica, MS, USA), a thrombin inhibitor, and the cells were pretreated with $200 \mu \mathrm{M}$ of a PAR1 inhibitor, SCH79797 $\left(\mathrm{C}_{23} \mathrm{H}_{25} \mathrm{~N}_{5} .2 \mathrm{HCl}\right.$, Abcam, Cambridge, MA, USA), as previously described [36, 37]. Thrombin receptor-activating peptide (TRAP, Sigma-Aldrich), a platelet agonist, was used as a positive control for platelet activation [24].

\section{Alternative complement pathway activation}

Detection of complement activation was conducted according to the methods described previously [34, 38]. Briefly, non-activated or activated platelets were washed once with Tyrode/PGE buffer (Tyrode's buffer with $1 \mu M$ PGE1 obtained from Sigma-Aldrich), centrifuged at $1200 \mathrm{~g}$ for $10 \mathrm{~min}$ at room temperature, and incubated with $50 \%$ plasma in 0.8 mM Mg-EGTA buffer (10 mM EGTA with $0.8 \mathrm{mM}$ $\left.\mathrm{MgCl}_{2}\right)$ to assess complement proteins activation. Instead of reaction buffers, $10 \mathrm{mM}$ EDTA was added, which binds calcium and magnesium ions in the plasma, to restrain potential complement activation as the negative control. The samples were incubated for $60 \mathrm{~min}$ at $37{ }^{\circ} \mathrm{C}$, and then the reactions were stopped by $3 \mu \mathrm{l}$ EDTA/PGE buffer (EDTA buffer with $1 \mu \mathrm{M}$ PGE1). After centrifugation at $1200 \mathrm{~g}$ for $10 \mathrm{~min}$ at room temperature, the supernatant was stored and quantitated with Quidel enzyme-linked immunosorbent assays (ELISAs) for human C3a, C5a, sC4d, and sC5b-9 (Quidel Corporation, San Diego, CA, USA). The remaining platelets were washed with Tyrode/ PGE buffer to reduce nonspecific adhesion of complement molecules, then incubated with antibodies to CD41, C3c and C5b-9, and analyzed by fluorescentactivated cell sorting (FACS), as described above.

The study protocol complied with the Declaration of Helsinki and was approved by the ethics committee of Peking University First Hospital. Written informed consent was obtained from each participant.

\section{Statistical analysis}

Results were presented as the mean $\pm \mathrm{SD}$ (for normally distributed data) or median and interquartile range (IQR, for non-normally distributed data), as appropriate. Difference in the paired samples was assessed using paired $t$ test or Wilcoxon's signed rank tests, as appropriate. Difference between unpaired groups was assessed using $t$ tests or nonparametric tests, as appropriate. Difference between multiple groups was assessed using the one-way ANOVA. Difference between non-independent data was assessed using generalized estimating equations. Statistical analyses were performed with the SPSS statistics software, version 15.0 (Chicago, IL, USA). The $p$ values less than 0.05 were considered significant.

\section{Results}

\section{Platelets are activated in active AAV patients}

Platelets from the patients and healthy donors were stained for CD62P. Among the 31 active AAV patient samples that were analyzed for CD62P expression, 19 were male and 12 were female, with an age of 59.4 \pm 13.2 years at diagnosis. Twenty-seven and four patients were MPO-ANCA and PR3-ANCA positive, respectively. The initial serum creatinine $(\mathrm{Scr})$ values were $456.8 \pm 258.6 \mu \mathrm{mol} / \mathrm{L}$. The initial BVAS levels were 19.5 \pm 6.2 (Table 1).

The percentages of CD62P-expressing platelets in AAV patients in active stage were significantly higher than that in remission and the normal controls $(15.8 \%[5.1 \%, 26.7 \%]$ vs. $8.9 \%[4.2 \%, 12 \%], p<0.05$; $15.8 \%[5.1 \%, 26.7 \%]$ vs. $5.7 \%[3.1 \%, 6.5 \%], p<0.0001$, respectively). Furthermore, among the 16 AAV patients with sequential blood samples from both active stage and remission, the percentages of CD62P-expressing platelets were significantly higher in AAV patients in active stage than those in remission $(20.4 \% \quad[12.7 \%, 28.9 \%] \quad$ vs. $8.0 \%$ [2.5\%,11.4\%], $p<0.0001)$, and all these 16 patients had a decrease in the percentages of CD62Pexpressing platelets in remission, compared with that in active stage (Fig. 1a), which was consistent with the above-mentioned results. There was no significant difference of the percentages of CD62P-expressing platelets among different induction therapy regimens in AAV patients.

Leukocytes from AAV patients and healthy blood donors were stained for CD45 and CD41a (the marker of platelets) in 22 of the above-mentioned 31 active AAV patients with a sufficient sample. Neutrophils, lymphocytes and monocytes were identified based on their characteristic light scatter and differential CD45 expression. The percentages of CD41a-positive neutrophils, lymphocytes and monocytes, i.e., neutrophil-, 
Table 1 General data of the 31 AAV patients in active stage

\begin{tabular}{|c|c|}
\hline Parameters & Value \\
\hline \multicolumn{2}{|l|}{ General clinical data } \\
\hline No. subjects & 31 \\
\hline Gender (M/F) & 19/12 \\
\hline Age & $59.4 \pm 13.2$ \\
\hline ANCA target antigen (MPO/PR3) & $29 / 3$ \\
\hline Initial Scr ( $\mu \mathrm{mol} / \mathrm{L})$ & $448.6 \pm 250.6$ \\
\hline Urinary protein (g/24 hr) & $0.76(00.5-2.01)$ \\
\hline BVAS & $18.3 \pm 5.7$ \\
\hline Renal involvement & $21(91.3 \%)$ \\
\hline Pulmonary involvement & $21(91.3 \%)$ \\
\hline ENT involvement & $6(26.1 \%)$ \\
\hline Nervous system involvement & $5(21.7 \%)$ \\
\hline \multicolumn{2}{|l|}{ Pathologic data } \\
\hline No. subjects & 20 \\
\hline \multicolumn{2}{|l|}{ Glomerular lesions } \\
\hline Total crescents & $58 \%(36-77 \%)$ \\
\hline Cellular crescents & $42 \%(26-57 \%)$ \\
\hline \multicolumn{2}{|l|}{ Tubulointerstitial lesions } \\
\hline Interstitial infiltration $(-/+/++/+++)$ & 0/6/14/0 \\
\hline Interstitial fibrosis $(-/+/++)$ & $1 / 6 / 13$ \\
\hline Tubular atrophy $(-/+/++)$ & $2 / 13 / 5$ \\
\hline \multicolumn{2}{|l|}{ Treatment data } \\
\hline Prednisone & 31 \\
\hline Methylprednisolone pulse & 17 \\
\hline Plasma exchange & 15 \\
\hline CTX (intravenous/oral) & $28 / 3$ \\
\hline
\end{tabular}

Abbreviations: $A A V$ antineutrophil cytoplasmic antibody-associated vasculitis, ANCA antineutrophil cytoplasmic antibody, MPO myeloperoxidase, PR3 protinase 3, Scr serum creatinine, BVAS Birmingham Vasculitis Activity Score, ENT ear, nose and throat, CTX cyclophosphamide

lymphocyte- and monocyte-platelet aggregates (abbreviated as NPA, LPA and MPA, respectively) were analyzed separately. The NPA, LPA and MPA percentages in the AAV patients in the active stage were significantly higher than those in the AAV patients in remission $(19.3 \%$ [5.8\%,27.2\%] vs. $6.3 \%$ [4.6\%, 7.2\%], $p<0.0001 ; 31.8 \%$ $[15.8 \%, 46.3 \%]$ vs. $14.2 \%[8.4 \%, 20.9 \%], p<0.001 ; 8.8 \%$ [5.9\%, $12.3 \%]$ vs. $5.9 \%[4.3 \%, 7 \%], p<0.01$; respectively) and in the normal controls $(19.3 \%[5.8 \%, 27.2 \%]$ vs. $7.7 \%$ [5.4\%,9.5\%], $p<0.0001 ; 31.8 \%[15.8 \%, 46.3 \%]$ vs. $14.5 \%$ [10.8\%, 18.7\%], $p<0.0001 ; 8.8 \%[5.9 \%, 12.3 \%]$ vs. $4.2 \%$ $[2.1 \%, 6.1 \%], \quad p<0.0001$; respectively) (Fig. 1b-d). Furthermore, the platelet-leukocyte aggregate levels in 11 AAV patients with sequential samples of both active stage and remission were compared. The neutrophil, lymphocyte and monocyte adhesion percentages were significantly higher in the active stage than in remission $(26.4 \%[17.8 \%$, $27.9 \%$ vs. $6.6 \%[4.8 \%, 8.1 \%], p<0.0001 ; 43.4 \%$ [31.2\%, $58.9 \%]$ vs. $12 \%$ [7\%,12.3\%], $p<0.0001 ; 10.4 \%$ [7.6\%, $12.3 \%]$ vs. $4.7 \%[4.1 \%, 6 \%], p<0.0001$; respectively); all 11 patients had decreased NPA, LPA and MPA levels in remission compared with the active stage (Fig. 1b-d).

Collectively, these data suggest that platelets are activated in patients with active AAV.

\section{Effect of the thrombin-PARs pathway in platelet activation by plasma from AAV patients}

We collected plasma samples from 14 active AAV patients before the initiation of immunosuppressive therapy for platelets stimulation. Among these 14 patients, 7 were male and 7 were female, with an average age of $52.0 \pm 13.0$ years at diagnosis. Seven and seven patients were MPO-ANCA and PR3-ANCA positive, respectively. The initial BVAS level was 20.6 \pm 7.1 . When the platelets were incubated with plasma from the active AAV patients, the CD62P-expressing platelet levels increased significantly compared with those incubated with plasma from the healthy donors $(97.7 \pm 3 \%$ vs. $1 \pm$ $0.2 \%, p<0.0001$ ) (Fig. 2).

To evaluate the potential role of the thrombinPARs pathway in platelet activation, thrombin inhibition and PAR1 blockage were performed. The plasma from active AAV patient was pretreated with $20 \mu \mathrm{M}$ PPACK to inhibit its potential thrombin activity. PPACK pretreatment led to a significant decrease in the CD62P-expressing platelets after stimulation with plasma of AAV patients $(97.7 \pm 3.0 \%$ vs. $2.7 \pm 1.0 \%, \quad p<0.0001)$. Furthermore, pre-incubation with $200 \mu \mathrm{M}$ SCH79797 induced a significant decrease in the CD62P expression level after stimulation with plasma of AAV patients $(97.7 \pm 3.0 \%$ vs. $5 \pm 1.4 \%, p<0.0001$ ) (Fig. 2).

Collectively, these results suggest that thrombin-PARs pathway contributes at least partially to platelet activation in AAV patients.

\section{Alternative complement pathway activation by AAV plasma-stimulated platelets}

After the platelets were activated by the plasma of AAV patients, $\mathrm{Ca} / \mathrm{Mg}$-Tyrode buffer was used to measure complement activation via all three pathways, i.e., the classical, mannose-binding lectin (MBL) and alternative pathways. In the liquid phase, the complement fragments $\mathrm{C} 3 \mathrm{a}, \mathrm{C} 5 \mathrm{a}$ and soluble membrane attack complex (MAC) sC5b-9 levels were significantly higher than those in the vehicle treatment $(2,921.5 \pm 295.7 \mathrm{ng} / \mathrm{ml}$ vs. $618.1 \pm 87.6 \mathrm{ng} / \mathrm{ml}, p<0.0001 ; 56.3 \pm 1.8 \mathrm{ng} / \mathrm{ml}$ vs. 14.8 $\pm 1.0 \mathrm{ng} / \mathrm{ml}, p<0.0001 ; 4425.3 \pm 243.8 \mathrm{ng} / \mathrm{ml}$ vs. $1445 \pm$ $67.2 \mathrm{ng} / \mathrm{ml}, p<0.0001$; respectively), whereas $\mathrm{sC4d}$, a common factor of the classical and mannose-binding 

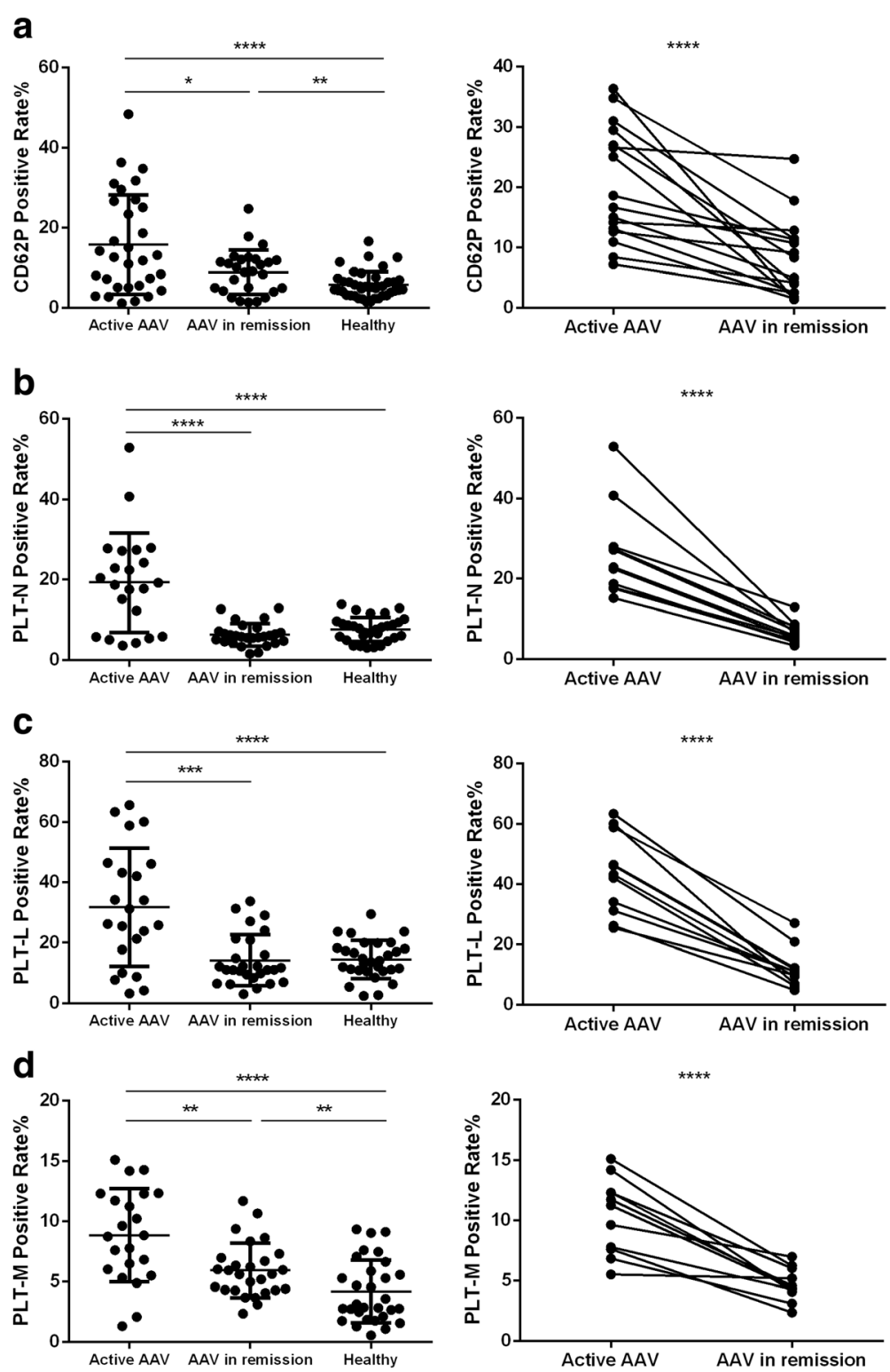

Fig. 1 Platelet activation profiles and leukocyte-platelet aggregates in patients with ANCA-associated vasculitis. a CD62P-expressing platelets. b Neutrophil-platelet aggregation. $\mathbf{c}$ Lymphocyte-platelet aggregation. d Monocyte-platelet aggregation. ${ }^{*} p<0.05,{ }^{* *} p<0.01,{ }^{* * *} p<0.001$, **** $p<0.0001$, unpaired and paired $t$ tests

lectin pathways, was comparable to that in the vehicle group $(7.0 \pm 0.3 \mathrm{ng} / \mathrm{ml}$ vs. $7.4 \pm 0.4 \mathrm{ng} / \mathrm{ml}, p=0.629)$. On the platelets, levels of adhesion complement fragment C3c, a cleavage product of $\mathrm{C} 3 \mathrm{~b}$ and the C5b-9 complex, were significantly higher than in the negative control samples $(23.1 \pm 1.7 \%$ vs. $5.9 \pm 0.8 \%, p<0.0001$; $22.7 \pm 1.6 \%$ vs. $5.9 \pm 0.8 \%, \quad p<0.0001 ;$ respectively) (Fig. 3).

Additionally, after platelets were activated by ANCA-positive plasma, Mg-EGTA buffer was used to selectively measure activation of the complement alternative pathway and not the classic or MBL pathways. In the fluid phase, the concentrations of the complement fragments, C3a, C5a and sC5b-9, were significantly higher than those in the vehicle samples $(1420.5 \pm 150.0 \mathrm{ng} / \mathrm{ml}$ vs. $618.1 \pm 87.6 \mathrm{ng} / \mathrm{ml}, p<0.0001$; $33.8 \pm 2.3 \mathrm{ng} / \mathrm{ml}$ vs. $14.8 \pm 1 \mathrm{ng} / \mathrm{ml}, p<0.0001 ; 3035.5 \pm$ $267.6 \mathrm{ng} / \mathrm{ml}$ vs. $1445 \pm 67.2 \mathrm{ng} / \mathrm{ml}, p<0.0001$; respectively). On the platelet surfaces, the $\mathrm{C} 3 \mathrm{c}$ and C5b-9 complex levels were significantly higher than in the negative control samples $(23.5 \pm 1.6 \%$ vs. $5.5 \pm 0.3 \%, p<0.0001$; $23.7 \pm 1.7 \%$ vs. $5.5 \pm 0.3 \%, p<0.0001$; respectively) (Fig. 4 ).

These results show that the alternative complement pathway is activated by activated platelets in AAV. 

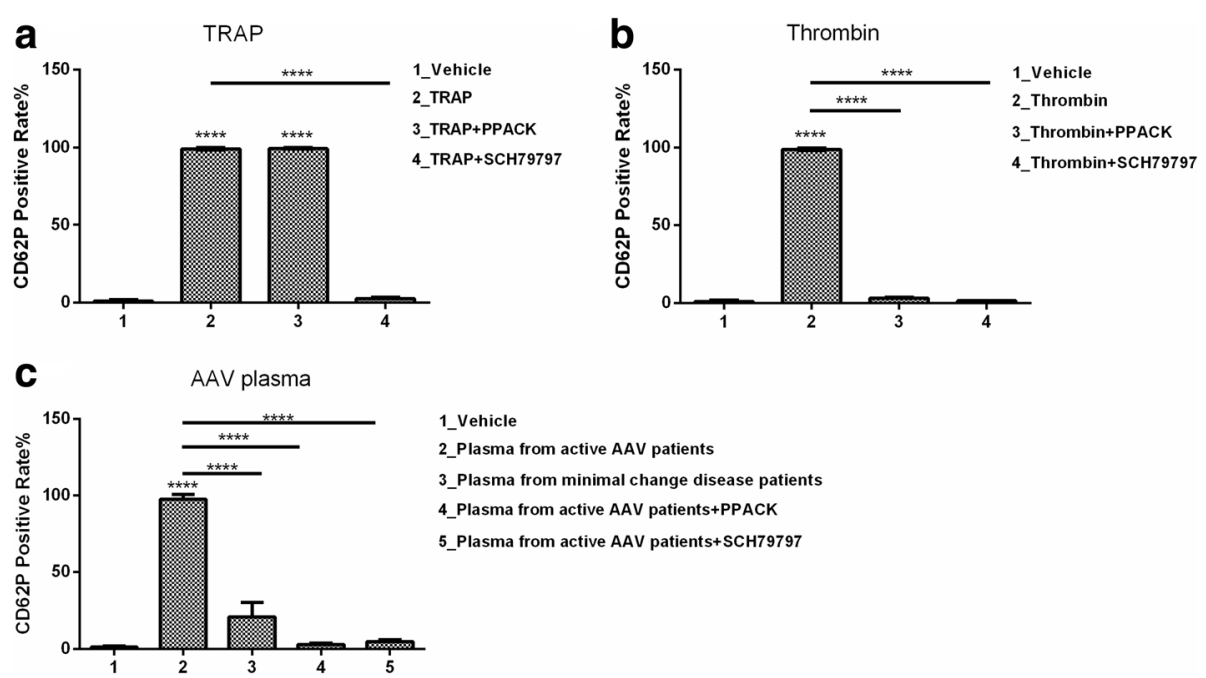

Fig. 2 Effect of the thrombin-PARs pathway on platelet activation in AAV. a CD62P expression on platelets activated by TRAP. b CD62P expression on platelets activated by thrombin. c CD62P expression on platelets activated by AAV plasma. ${ }^{* * *} p<0.0001$, unpaired $t$ test
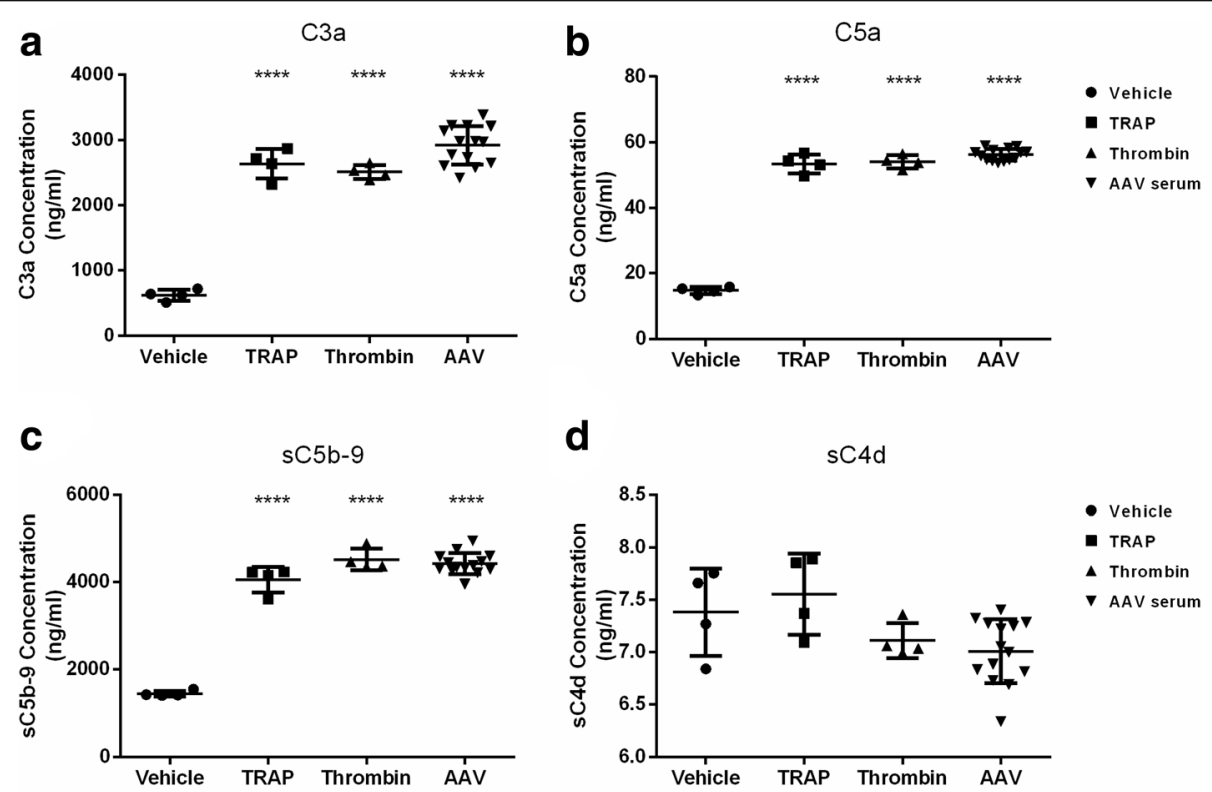

d

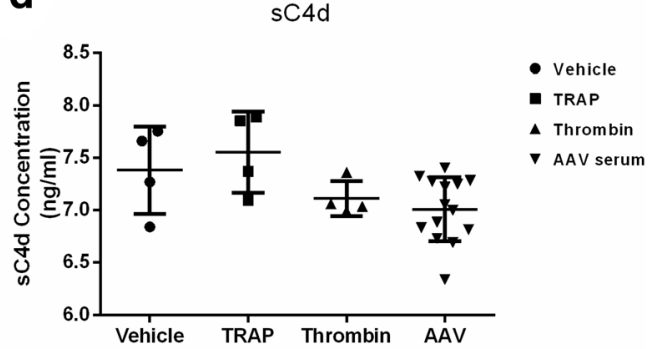

e

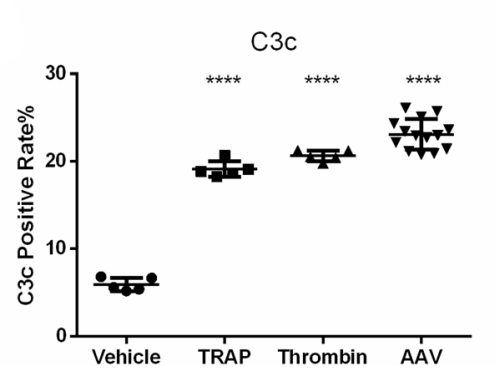

f

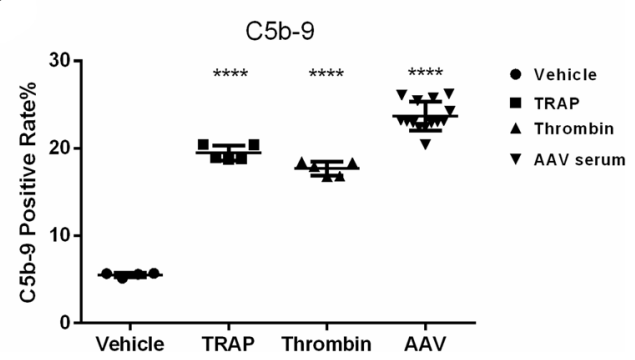

Fig. $\mathbf{3}$ In Tyrode's buffer, the complement system was activated by AAV-plasma stimulated platelets. a Generation of C3a by activated platelets. $\mathbf{b}$ Generation of C5a by activated platelets. c Generation of sC5b-9 by activated platelets. $\mathbf{d}$ Generation of sC4d by activated platelets. e Deposition of C3c on activated platelets. $\mathbf{f}$ Deposition of C5b-9 on activated platelets. ${ }^{* * *} p<0.0001$, compared with the vehicle group (unpaired $t$ test) 

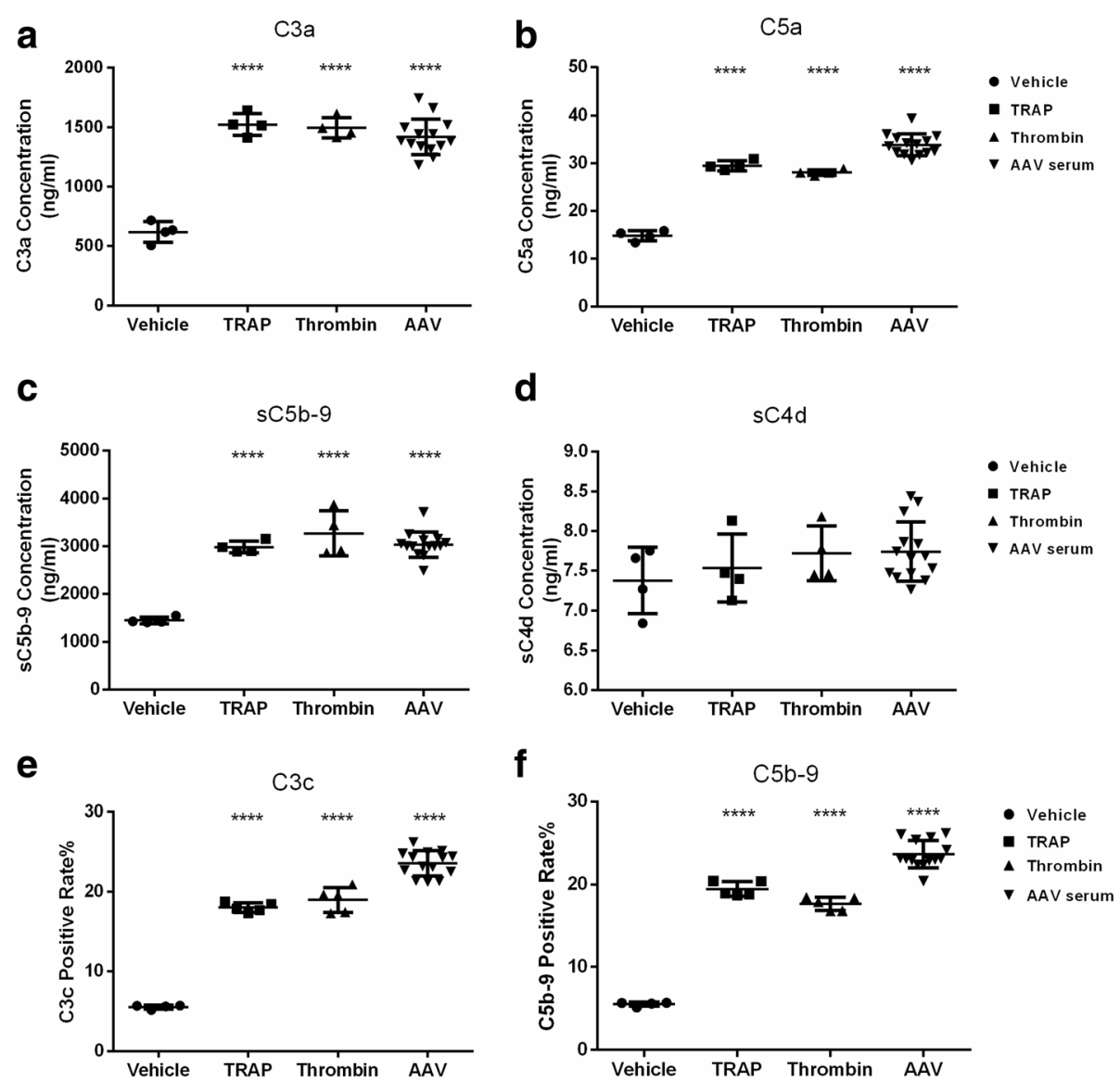

Fig. 4 In EGTA buffer, the alternative pathway of complement system was activated by AAV-plasma stimulated platelets. a Generation of C3a by activated platelets. $\mathbf{b}$ Generation of C5a by activated platelets. c Generation of sC5b-9 by activated platelets. $\mathbf{d}$ Generation of sC4d by activated platelets. e Deposition of C3c on activated platelets. $\mathbf{f}$ Deposition of C5b-9 on activated platelets. ${ }^{* * * *} p<0.0001$, compared with the vehicle group (unpaired $t$ test)

\section{Discussion}

Platelets are linked to the pathogenesis of many autoimmune diseases. Recently, Tomasson et al. reported soluble P-selectin (CD62P) as a disease activity marker of AAV [19], and Willeke et al. reported increased platelet counts in active AAV [12]. Our previous study also found that active AAV patients had elevated platelet counts in peripheral blood [10].

To the best of our knowledge, this is the first study to demonstrate that active AAV patient plasma can activate platelets. This activation is, at least partially, mediated by the thrombin-PARs pathway. Many studies suggested a hypercoagulable state in AAV patients [1-6]. Our recent study found that $\mathrm{C} 5 \mathrm{a}$, in combination with ANCA, can stimulate neutrophil to release tissue factor and thus lead to thrombin generation [11]. Thus, it is reasonable to assume a higher thrombin level in the circulation of AAV patients [10,11]. Thrombin inhibition and PARs blockade resulted in a significantly lower percentage of CD62P-expressing platelets, indicating that the
thrombin-PARs pathway plays an important role in platelet activation in AAV. A variety of studies reported that upon activation, platelets produce and release stored cytokines, chemokines and polyphosphates to recruit leukocytes and progenitor cells to inflammation sites. Additionally, they express adhesion molecules that interact with other immune cells, and they release proinflammatory, anti-inflammatory, angiogenic and microparticle mediators into the circulation to orchestrate immune responses [13-16]. Our findings may potentiate platelets as an inflammatory effector cell in the pathogenesis of AAV.

Another important finding in our study is that platelets, after being activated by the plasma of AAV patients, are sufficient to activate the alternative pathway of complement system in the fluid phase as well as on the surface of platelets. Activation of the complement alternative pathway is a crucial aspect in the pathogenesis of AAV. The alternative pathway aggravated several inflammatory cytokines to augment and sustain acute 


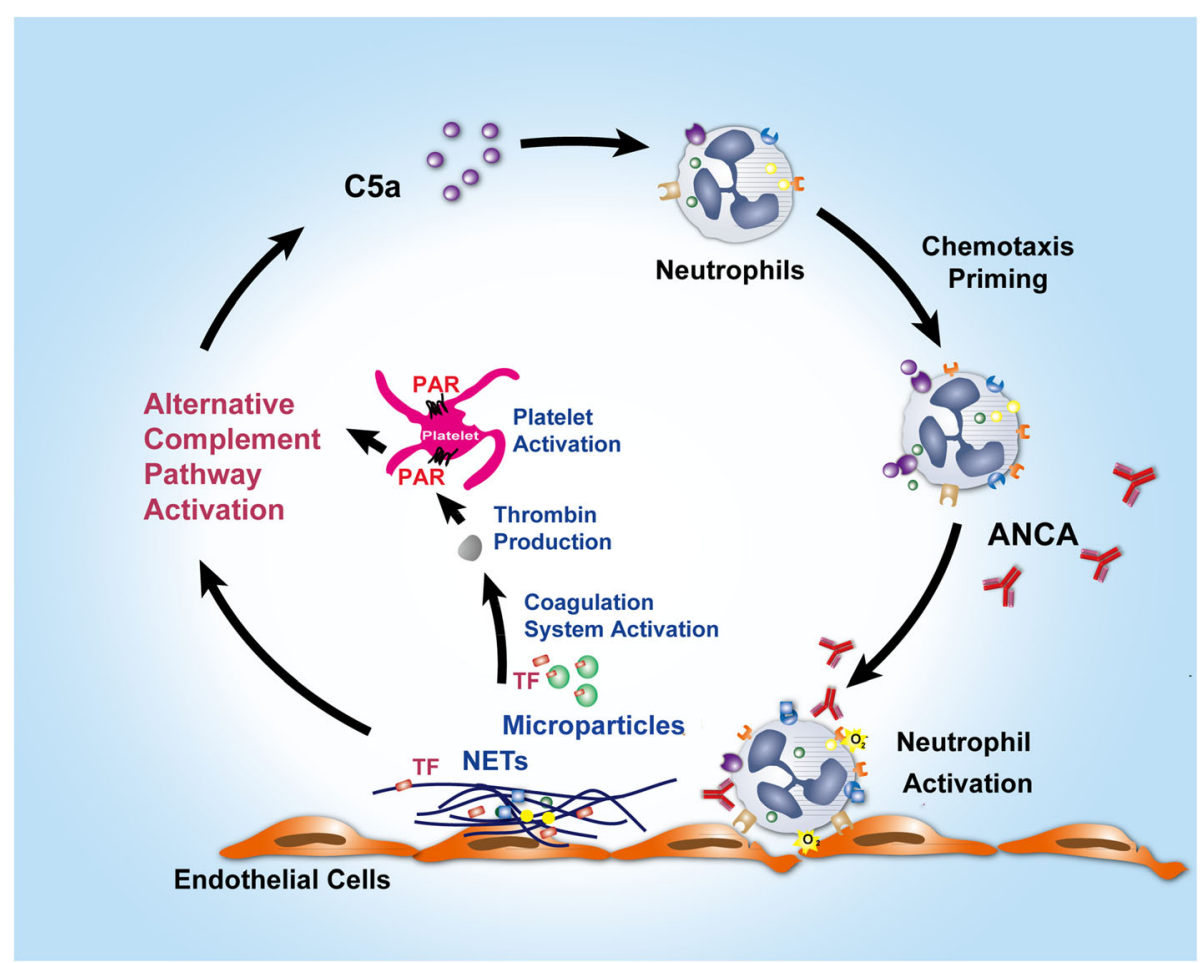

Fig. 5 The proposed cross-talk mechanism among ANCA, neutrophils, complement, and platelets in the pathogenesis of AAV. Neutrophil stimulation with cytokines (such as C5a or TNF-a) and ANCA results in respiratory burst and degranulation, which leads to the release of tissue factor (TF)-bearing microparticles and NETs that subsequently activate the coagulation system and generate thrombin. Thrombin can activate platelets through PARs. Such activated platelets can activate the alternative complement pathway. Additionally, activated neutrophils can also activate the alternative complement pathway via their cell membranes, microparticles, and NETs. This leads to the generation of more C5a, establishing a self-fueling inflammatory amplification loop leading to the vasculitic injury

inflammation in AAV and may be a pathogenic mechanism. It was previously considered that in AAV, complement alternative pathway activation resulted from neutrophil activation $[1,4,5]$. The current study provides another novel mechanism for alternative complement pathway activation in AAV.

Cumulative evidence demonstrated that the ANCA, neutrophil, and the complement alternative pathway positive feedback loop play crucial roles in the pathogenesis of AAV [39, 40]. Our previous study reported that $\mathrm{C} 5 \mathrm{a}$-primed neutrophils activated by ANCAs release tissue factor (TF)-expressing neutrophil microparticles and neutrophil extracellular traps, which subsequently activate the coagulation system and generate thrombin [11]. Our findings in the current study further demonstrate that the thrombin in plasma of AAV patients can activate platelets, and such stimulated platelets can subsequently activate the alternative complement pathway. These emerging functions of platelets bridge neutrophils and the alternative pathway of complement activation, which establish an especially self-fueling inflammatory amplification loop leading to vasculitic injury. The proposed mechanism of the cross-talk among
ANCA, neutrophils, complement particles, and platelets in the pathogenesis of AAV is shown in Fig. 5.

\section{Conclusions}

In conclusion, our study reveals that platelets are activated in AAV patients. Such activation is partially attributed to the thrombin-PARs pathway, which may account for the hypercoagulable state in active AAV. Furthermore, activated platelets trigger the alternative complement pathway. These findings support the possible roles of platelets in the pathogenesis of AAV and indicate their potential as novel therapeutic targets.

\section{Abbreviations \\ AAV: ANCA-associated vasculitis; ANCA: Antineutrophil cytoplasmic antibody; AZA: Azathioprine; BVAS: Birmingham Vasculitis Activity Score; \\ CTX: Cyclophosphamide; EGPA: Eosinophilic granulomatosis with polyangiits; ELISA: Enzyme-linked immunosorbent assay; ENT: Ear, nose, throat; \\ FACS: Fluorescent-activated cell sorting; GPA: Polyangiitis; GPRP: Gly-Pro-Arg- Pro; MCD: Minimal change disease; MPA: Microscopic polyangiitis; \\ MPO: Myeloperoxidase; PARs: Protease-activated receptors; PPACK: D-Phe-Pro- Arg- $\mathrm{CH}_{2} \mathrm{Cl}$; PR3: Protinase 3; PRP: Platelet-rich plasma; Scr: Serum creatinine; TF: Tissue factor; TRAP: Thrombin receptor-activating peptide; VTE: Venous thromboembolic events}

\section{Funding}

This study was supported by the grant from the National Key Research and Development Program (No. 2016YFC0906102), two grants from the National 
Natural Science Fund of China (No. 81425008 and 81621092) and the grant of University of Michigan Health System and Peking University Health Sciences Center Joint Institute for Translational and Clinical Research, and the Program of Changjiang Scholar (BMU2017CJ002).

\section{Availability of data and materials}

The datasets used or analyzed during the current study are available from the corresponding author on reasonable request.

\section{Authors'contributions}

DM and DYL collected samples and clinical information, carried out platelet detection in patients, platelet activation and complement pathways activation, data analysis, and wrote the manuscript. $\mathrm{MC}$ and $\mathrm{MHZ}$ designed and directed the study. All authors have read and approved the final manuscript.

\section{Ethics approval and consent to participate}

The research was approved by the clinical research ethics committee of the Peking University First Hospital. All patients provided written informed consent including consent to publish and report individual patient data.

\section{Consent for publication}

Not applicable.

\section{Competing interests}

The authors declare that they have no competing interests.

\section{Publisher's Note}

Springer Nature remains neutral with regard to jurisdictional claims in published maps and institutional affiliations.

\section{Author details}

${ }^{1}$ Renal Division, Department of Medicine, Peking University First Hospital, Beijing 100034, China. ${ }^{2}$ Institute of Nephrology, Peking University, Beijing 100034, China. ${ }^{3}$ Key Laboratory of Renal Disease, Ministry of Health of China, Beijing 100034, China. ${ }^{4}$ Key Laboratory of Chronic Kidney Disease Prevention and Treatment, Ministry of Education, Peking University, Beijing 100034, China. ${ }^{5}$ Peking-Tsinghua Center for Life Sciences, Peking University, Beijing 100871, China.

\section{Received: 7 August 2017 Accepted: 24 October 2017}

\section{Published online: 15 November 2017}

\section{References}

1. Xiao H, Schreiber A, Heeringa P, Falk RJ, Jennette JC. Alternative complement pathway in the pathogenesis of disease mediated by anti-neutrophil cytoplasmic autoantibodies. Am J Pathol. 2007;170(1):52-64.

2. Xing GQ, Chen M, Liu G, Heeringa P, Zhang JJ, Zheng X,EJ, Kallenberg CG, Zhao $\mathrm{MH}$. Complement activation is involved in renal damage in human antineutrophil cytoplasmic autoantibody associated pauci-immune vasculitis. J Clin Immunol. 2009;29(3):282-91.

3. Gou SJ, Yuan J, Chen M, Yu F, Zhao MH. Circulating complement activation in patients with anti-neutrophil cytoplasmic antibody-associated vasculitis. Kidney Int. 2013;83(1):129-37.

4. Camous L, Roumenina L, Bigot $S$, Brachemi S, Fremeaux-Bacchi V, Lesavre $P$, Halbwachs-Mecarelli L. Complement alternative pathway acts as a positive feedback amplification of neutrophil activation. Blood. 2011;117(4):1340-9.

5. Wang $\mathrm{H}$, Wang $\mathrm{C}$, Zhao $\mathrm{MH}$, Chen M. Neutrophil extracellular traps can activate alternative complement pathways. Clin Exp Immunol. 2015;181(3):518-27.

6. Merkel PA, Lo GH, Holbrook JT, Tibbs AK, Allen NB, Jr JCD, Hoffman GS, McCune WJ, Clair EWS, Specks U, et al. Brief communication: high incidence of venous thrombotic events among patients with Wegener granulomatosis: the Wegener's Clinical Occurrence of Thrombosis (WeCLOT) Study. Ann Intern Med. 2005;142(8):620-6.

7. Weidner S, Hafezi-Rachti S, Rupprecht HD. Thromboembolic events as a complication of antineutrophil cytoplasmic antibody-associated vasculitis. Arthritis Rheum. 2006:55(1):146-9.

8. Stassen PM, Derks RP, Kallenberg CG, Stegeman CA. Venous thromboembolism in ANCA-associated vasculitis-incidence and risk factors. Rheumatology (Oxford). 2008;47(4):530-4.
9. Allenbach Y, Seror R, Pagnoux C, Teixeira L, Guilpain P, Guillevin L, French Vasculitis Study Group. High frequency of venous thromboembolic events in Churg-Strauss syndrome, Wegener's granulomatosis and microscopic polyangiitis but not polyarteritis nodosa: a systematic retrospective study on 1130 patients. Ann Rheum Dis. 2009;68(4):564-7.

10. Ma TT, Huang YM, Wang C, Zhao MH, Chen M. Coagulation and fibrinolysis index profile in patients with ANCA-associated vasculitis. PLoS One. 2014;9(5):e97843.

11. Huang YM, Wang $H$, Wang C, Chen M, Zhao MH. Promotion of hypercoagulability in antineutrophil cytoplasmic antibody-associated vasculitis by $\mathrm{C} 5 \mathrm{a}$-induced tissue factor-expressing microparticles and neutrophil extracellular traps. Arthritis Rheumatol. 2015;67(10):2780-90.

12. Willeke $P$, Kumpers $P$, Schluter $B$, Limani $A$, Becker $H$, Schotte $H$. Platelet counts as a biomarker in ANCA-associated vasculitis. Scand J Rheumatol. 2015;44(4):302-8.

13. Semple JW, Italiano Jr JE, Freedman J. Platelets and the immune continuum Nat Rev Immunol. 2011;11(4):264-74.

14. Ware J, Corken A, Khetpal R. Platelet function beyond hemostasis and thrombosis. Curr Opin Hematol. 2013;20(5):451-6.

15. Morrell CN, Aggrey AA, Chapman LM, Modjeski KL. Emerging roles for platelets as immune and inflammatory cells. Blood. 2014;123(18):2759-67.

16. Smyth SS, McEver RP, Weyrich AS, Morrell CN, Hoffman MR, Arepally GM, French PA, Dauerman HL, Becker RC. Platelet Colloquium Participants. Platelet functions beyond hemostasis. J Thromb Haemost. 2009;7(11):1759-66.

17. Meijer-Jorna LB, Mekkes JR, van der Wal AC. Platelet involvement in cutaneous small vessel vasculitis. J Cutan Pathol. 2002;29(3):176-80.

18. Rondina MT, Weyrich AS, Zimmerman GA. Platelets as cellular effectors of inflammation in vascular diseases. Circ Res. 2013;112(11):1506-19.

19. Tomasson G, Lavalley M, Tanriverdi K, Finkielman JD, Davis Jr JC, Hoffman GS, McCune WJ, St Clair EW, Specks U, Spiera R, et al. Relationship between markers of platelet activation and inflammation with disease activity in Wegener's granulomatosis. J Rheumatol. 2011;38(6):1048-54.

20. Kapsoritakis ANKM, Sfiridaki A, Potamianos SP, Kosmadaki MG, Koutroubakis IE, Kouroumalis EA. Mean platelet volume: a useful marker of inflammatory bowel disease activity. Am J Grastroenterol. 2001;96(3):776-81.

21. Kisacik B, Tufan A, Kalyoncu U, Karadag O, Akdogan A, Ozturk MA, Kiraz S, Ertenli I, Calguneri M. Mean platelet volume (MPV) as an inflammatory marker in ankylosing spondylitis and rheumatoid arthritis. Joint Bone Spine. 2008;75(3):291-4.

22. LE Davey MG. Actions of thrombin and other coagulant and proteolytic enzymes on blood platelets. Nature. 1967;216(5118):857-8.

23. Kahn ML, Nakanishi-Matsui M, Shapiro MJ, Ishihara H, Coughlin SR. Proteaseactivated receptors 1 and 4 mediate activation of human platelets by thrombin. J Clin Invest. 1999;103(6):879-87.

24. Linden MD. Platelet physiology. Methods Mol Biol. 2013;992:13-30.

25. Jennette JC, Falk RJ, Bacon PA, Basu N, Cid MC, Ferrario F, Flores-Suarez LF, Gross WL, Guillevin L, Hagen EC, et al. 2012 revised International Chapel Hill Consensus Conference Nomenclature of Vasculitides. Arthritis Rheum. 2013:65(1):1-11.

26. Luqmani R, Bacon P, Moots R, Janssen B, Pall A, Emery P, Savage C, Adu D. Birmingham Vasculitis Activity Score (BVAS) in system necrotizinig vasculitis. QJM. 1994;87(11):671-8.

27. Hellmich B, Flossmann O, Gross WL, Bacon P, Cohen-Tervaert JW, Guillevin L Jayne D, Mahr A, Merkel PA, Raspe H, et al. EULAR recommendations for conducting clinical studies and/or clinical trials in systemic vasculitis: focus on anti-neutrophil cytoplasm antibody-associated vasculitis. Ann Rheum Dis. 2007;66(5):605-17.

28. Jennette JC. Rapidly progressive crescentic glomerulonephritis. Kidney Int. 2003;63(3):1164-77.

29. Li ZY, Chang DY, Zhao MH, Chen M. Predictors of treatment resistance and relapse in antineutrophil cytoplasmic antibody-associated vasculitis: a study of 439 cases in a single Chinese center. Arthritis Rheumatol. 2014;66(7):1920-6.

30. Linden MD. Platelet flow cytometry. Methods Mol Biol. 2013;992:241-62.

31. Furie B, Furie BC, Flaumenhaft R. A journey with platelet P-selectin: the molecular basis of granule secretion, signalling and cell adhesion. Thromb Haemost. 2001;86(1):214-21.

32. Larsen E, Gary C, Furie BC, Erban JK, Bonfanti R, Wagner DD, Furie B. PADGEM protein: a receptor that mediates the interaction of activated platelets with neutrophils and monocytes. Cell. 1989;59(2):305-12.

33. Barnard MR, Krueger LA, Frelinger AL, Furman MI, Michelson AD. Whole blood analysis of leukocyte-platelet aggregates. Curr Protoc Cytom. 2003;6:6.15. 
34. Del Conde I, Cruz MA, Zhang H, Lopez JA, Afshar-Kharghan V. Platelet activation leads to activation and propagation of the complement system. Exp Med. 2005;201(6):871-9.

35. Michelson AD. Platelet activation by thrombin can be directly measured in whole blood through the use of the peptide GPRP and flow cytometry, methods and clinical applications. Blood Coagul Fibrinolysis. 1994;5(1):121-31.

36. Boilard E, Pare G, Rousseau M, Cloutier N, Dubuc I, Levesque T, Borgeat P, Flamand L. Influenza virus H1N1 activates platelets through FcgammaRIIA signaling and thrombin generation. Blood. 2014;123(18):2854-63.

37. El Eter EA, Aldrees A. Inhibition of proinflammatory cytokines by SCH79797, a selective protease-activated receptor 1 antagonist, protects rat kidney against ischemia-reperfusion injury. Shock. 2012;37(6):639-44.

38. Saggu G, Cortes C, Emch HN, Ramirez G, Worth RG, Ferreira VP. Identification of a novel mode of complement activation on stimulated platelets mediated by properdin and $\mathrm{C} 3(\mathrm{H} 2 \mathrm{O})$. J Immunol. 2013;190(12):6457-67

39. Schreiber A, Xiao H, Jennette JC, Schneider W, Luft FC, Kettritz R. C5a receptor mediates neutrophil activation and ANCA-induced glomerulonephritis. J Am Soc Nephrol. 2009;20(2):289-98.

40. Falk RJ, Jennette JC. Anti-neutrophil cytoplasmic autoantibodies with specificity for myeloperoxidase in patients with systemic vasculitis and idiopathic necrotizing and crescentic glomerulonephritis. N Engl J Med. 1988;318(25):1651-7

\section{Submit your next manuscript to BioMed Central and we will help you at every step:}

- We accept pre-submission inquiries

- Our selector tool helps you to find the most relevant journal

- We provide round the clock customer support

- Convenient online submission

- Thorough peer review

- Inclusion in PubMed and all major indexing services

- Maximum visibility for your research

Submit your manuscript at www.biomedcentral.com/submit 